\section{COMPETINDO PELO FUTURO}

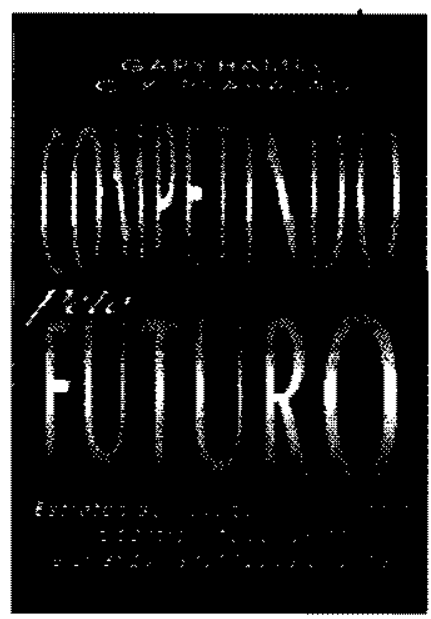

de GARY HAMEL e C. K. PRAHALAD

Rio de Janeiro: Campus, $1995,378 p$.

por Cristiano Lúcio de Souza, Bacharel em Administração e Administrador do Instituto Estadual de Desenvolvimento de Recursos Humanos, Belo Horizonte, MG.

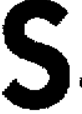
trategic intent $e$ The core competence of the corporation são, além de best sellers, premiados artigos de Gary Hamel, da London Business School e C. K. Prahalad, da University of Michigan. Publicados na Harvard Business Review, esses artigos têm desafiado executivos a estancar o processo nãocompensador de downsizing (ultimamente um beco sem saída) e a entrar no domínio dinâmico da transformação da indústria e da regeneração estratégica.

Poderosas e muito acatadas, as idéias e as metodologias de Hamel e Prahalad, experts na dinâmica da análise de mercado e nas estratégias e estruturas empresariais, vêm ultrapassando muitas das práticas gerenciais padröes e tornando obsoletos modelos convencionais de estratégia e crescimento. Ao mesmo tempo que novas realidades competitivas estão rompendo fronteiras da indústria, o pensamento dos dois consultores está gerando uma nova linguagem estra. tégica.

Foi, em parte, para deixar claro o que pensavam dos artigos supracitados, que os dois autores, já de notável reputação, escreveram Competindo pelo futu$\mathrm{ro}_{0}$ publicado originalmente, em setembro de 1994, pela Harward Business School Press. Esta obra, já há muito tempo esperada nos EUA, tem recebido, nesse país, muitos elogios. "É o melhor livoro de gerência do ano", escreveu a Business Week. "Se só há lugar para um livro de gerência na sua estante, por ano, entīo este é o Iivro", afirma The Washington Post. "[Hamel e Prahalad] procuram reabilitar a estratégia, através da reinvenção virtual de sua prática", registrou a Industry Week. Segundo a Entrepreneur Magazine, "este ê um dos onze livros de negócios que você nấo pode perder (..) leitura necessária a todo empreendedor".

Competindo pelo futuro destina-se tanto aos que estăo saturados de reengenharia, reestruturaçāo, cortes de custos e downsizing, quanto para os que arduamente já utilizaram essas técnicas e necessitam do fundamental para o sucesso. Ou seja, o livro muda o foco do processo da reengenharia para o da reinvenção industrial; da redução de despesas gerais, para a regeneração de estratêgias; da viabilidade a curto pra$\mathrm{zo}$, para a possibilidade a longo prazo; dos acordos de negócios, para o crescimento orgânico; da alocaçăo de recursos, para a alavancagem de recursos; do downsizing, para a construção.

Os pensadores afirmam: "A defasagem entre a teoria e a observaçäo (...) fot a origem deste livro. Escrevenos este livo em uma epoca em que as empresas estavam eliminan. do os departamentos de estratégia corporativa, as empresas de consultoria estavam engajadas com mais frequência na methoria da eficiência operacional do que nos planos estratégicos e muitas empresas estavam correndo para o downsizing, em vez de criar os mercados e setores de ama " nhã. Talvez não seja exagero afirmar que a estratégia estava em crise. Nossa meta, neste livro, é ampliar o conceito de estratégia de modo a permitir que ele inclua, de forma mais abrangente, a realidade competitiva emergente - uma realidade na qual a meta é transformar setores, näo apenas organizaçōes; una realidade na gual ser cada vez methor näo basta; uma realidade na qual una empresa incapaz de imaginar ofuturo năo estará lá para desfrutar dele".

Hamel e Prahalad argumentam que a maior vantagem competitiva de uma empresa ể a visăo do futuro. Toda a reengenharia no mundo não salvará a empresa que não refletir sobre o que acontecerá nos próximos dez anos. A empresa que primeiro chegar ao futuro ganhará a concorrência.

De início, entăo, as empresas devem investir na reflexăo sobre seu futuro. Os autores ensinam as organizaçöes como desenvolver a necessária capacidade de previsão para configurar, proativamente, a evolução industrial.

Mas isso não é suficiente. As empresas desejosas de inovar precisam quebrar barreiras, forçar suas unidades a trabalharem juntas e a formarem alianças com suas rivais. Elas precisam alcançar uma "diversidade genética" para criar mercados. Assim, Hamel e Prahalad mostram à empresa como descobrir caminhos para "alavancar recursos" necessários para o alcance de metas, a despeito das restriçóes financeiras; como estabelecer uma "intenção estratégica" ex- 
tensa e mobilizar a organizaçâo inteira em sua procura, e como estender as fronteiras da "imaginação empresarial", revitalizando o processo da criaçâo de negócios, o que é difícil de compreender.

Os autores também ajudam a desenvolver um ponto de vista no qual "competências essenciais" podem ser construídas para o futuro. Assim, uma empresa não deverá se preocupar em lançar um produto que conquiste o mundo, mas em criar uma especie de competência que a ajude a dominar o mercado.

Em suma, a visão do futuro ajuda o patrão a enxergar a empresa como um "porta-fólio" de recursos, e não como uma coleçāo de unidades independentes, e também a mudar a organização e a criar mexcados futuros.

Paralelamente a Competindo pelo futuro, tem surgi$\mathrm{do}_{x}$ na América do Norte, novo entendimento da mentalidade empresarial e das habilidades necessárias para as organizaçōes competirem com sucesso, no século XXI. Creative destruction, de Richard L. Nolan e David C. Croson, Levers of control, de Robert Simonse Waves of change, de James L. McKenney, são livros que, ao lado do de Hamel e Prahalad - os nomes mais influentes sobre estratégia no Ocidente -, falam de questôes relativas à transformação organizacional, convidando os leitores a pensar.

De um ponto de vista mais crítico, Hamel e Prahalad indicam o óbvio. Mas as empresas hoje estato num terreno minado por modismos e verborragia. Assim, uma das qualidades da obra é ser oportuna.

Competindo pelo futuro, segundo os autores, "năo um lioro para diletintes; nâo se destina simplesmente aos intelectuais e curiosos. É um guia para os que näo se contentam em seguir a corrente, para os que acreditam que a melhor forma de wencer é reescrever as regras, para os aue não têm medo de desafiar a ortodoxia, para os que estäo mais inclinados a construir do que a eliminar, para os mais preocupados em fazer a diferença do que en desenvolver uma carreira pessoal e para os que estão absolutamente comprometidos com a vontade de chegar primeiro ao futuro".

$O$ livro está obtendo sucesso por ser importante. Para os clientes, cria produtos e serviços näo imaginados, mas que, em breve, serão essenciais. Para os executivos, cria a oportunidade de, mais que fazer carreira, deixar um legado. Para os empregados, abre vias para aspiraçóes e contribuiçóes pessoais.

Se, por um lado, Competindo pelo futuro está grandemente fundamentado na experiência, em todo o mundo, de empresas que conseguiram superar a desvantagem de recursos e galgar posiçōes de liderança mundial, por outro, as idéias otimistas de Hamel e Prahalad, claramente expostas na obra, já vêm sendo usadas por muitas organizações importantes no Primeiro Mundo.

\section{MANUAL DE SOBREVIVẾNCIA PARA SÓCIOS E HERDEIROS: A EXPERIÉNCIA DA DPZ, DO GRUPO VICUNHA, DO LABORATÓRIO FLEURY E DA MÉTODO ENGENHARIA}

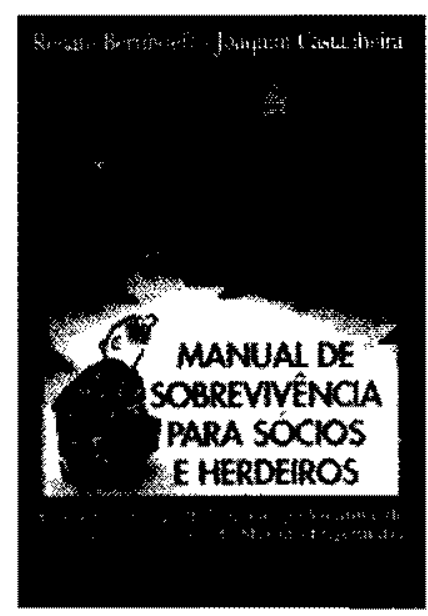

de RENATO BERNHOEFT E JOAQUIM CASTANHEIRA Säo Paulo: Nobel, 1995, 136p.

por Fabio Abilas, Graduando em Administração na Universidade Estadual de Maringá, PR.

$\mathbf{N}$ o Brasil, estima-se que a grande maioria das empresas familiares conseguem, em seu processo sucessorio, chegar somente até a terceira geração. No entanto, há casos que não chegam a esta. Os exemplos estão aî: Mattarazzo, Brandalise, Hermes Macedo etc. Problemas de sucessão, incompatibilidade de interesses, gestäo com princípios que não condizem com o pensamento do fundador, entre outros, sāo causas que desestruturam grandes grupos e deixam, no ax, perguntas e exclamaçöes como "com um império daquele?", "mas a empresa era sólida!", para as quais todos gostariam de ter respostas.

O problema é que a sucessäo familiar no Brasil é pouco discutida em termos de literatura, talvez porque algumas indústrias estejam chegando só recentemente ao seu centenário, o que torna a industrializaçâo brasileira jovem em relaçăo à dos países desenvolvidos. Mas năo se pode deixar de discutir problemas como o da preparaçăo adequada dos filhos para 